\title{
Rural housing as field of modernist experiences
}

\author{
Alexandra Cardoso ${ }^{1,1}$, Alexandra Trevisan ${ }^{1}$, Rute Figueiredo ${ }^{1}$, and Maria Helena Maia ${ }^{1}$ \\ ${ }^{1}$ Escola Superior Artística do Porto, Centro de Estudos Arnaldo Araújo, Porto, Portugal
}

\begin{abstract}
The Portuguese proposal to CIAM X (Dubrovnik 1956) was focused on the issue of rural planning. A new village was established among a set of existing ones, working as a structural core. The vernacular influence was clearly present through the images of Trás-osMontes (Survey on Portuguese Regional Architecture) used as a reference source for the new house typology. In addition to the vernacular, one can also identify modern references, in both Portugal and Spain, within the scope of internal colonization in the $20^{\text {th }}$ century, regarding the settlement of the Portuguese agricultural colonies (1920smid1950s) and the pueblos in Spain (1940s-1971), which had significance for the contemporary countryside image. Considering "the evolutive house" of the Portuguese proposal in CIAM X, or the modular solutions of the colonization settlements, one can find examples lying between the trendy and those in rooted architectural culture. In this paper, we analysed the rural 20th century housing idea present in the internal Iberian colonization settlements and in the ideological and political context under the dictatorial regimes. Using a comparative method, two case studies were examined in order to identify and abstract through cross-referencing main rural directions in the different Iberian contexts, and to frame common factors or different experiences, in the application of the planning schemes in both settlement and housing attributes.
\end{abstract}

Key words: Rural house, Iberian internal colonization, Modernist landscape

\section{The field: a meeting point between the vernacular and the modern}

In 1956, the Congrès Internationaux d'Architecture Moderne (CIAM) faced a significant challenge. The normative codes defined in the Charte d'Athenes, the Grille CIAM, the functionalist conventions, the analytical methodology to read and to define the city, and the modernist socio-political values that once drove the congress were undermined by the group of young architects Team $X^{2}$, in a series of strong confrontations at the

\footnotetext{
${ }^{1}$ Corresponding author: alex.c@sapo.pt

2 Designation adopted in 1954 by the CIAM X Committee, initially composed by Jaap Bakema,

Peter Smithson, Georges Candilis and Rolf Guttmann, in charge of preparing the congress. Other
} 
$10^{\text {th }}$ congress held in Dubrovnik. The call by Team $X$ for "a more humanistic approach to the habitat", in which "the rural world emerged as a reference for the creation of a harmonic relationship between the individual and the community" [1] was symptomatic of the socio-economic and cultural tensions that crossed different spheres of society in this period.

In line with the debate on rural planning, the CIAM's Portuguese team shaped a plan for a rural community in the Northeast, "that fostered the relationship between modern language and the features of vernacular tradition of the region".[2] A novel community village was devised (inside the team it was called the "CIAM village"), functioning as a structural core connected to a set of other existing settlements, and as such contributing to maintain the inhabitants in their own environment and to improve their living conditions [3].

Here, the solution proposed for a new rural house typology took Portuguese regional architecture as a major referential source. The allusion to the local traditions, in terms of morphology, type of settlement, systems of construction, ways of dwelling, rested on two key experiences shared very broadly by the community of architects of that time.

The first was the broad knowledge of the housing vernacular models collected in the Survey on Portuguese Regional Architecture [4], in which most of the team were involved. There was a consensus that the vernacular manifested the synthesis between the construction, the place in which it was inserted, the organization of the domestic space and the rational use of local materials. If the vernacular was taken as a model from which to draw the "indispensable premises to embody the whole contemporary orientation on habitat" [5: 12], this means that, from the Iberian viewpoint, "modern architecture [would be] a return to the pure and traditional forms of the Mediterranean" [6].

The second, was the practical knowledge acquired from the wide process, started in the late-1930s, of the internal colonization in Iberia, developed under the action of the Junta de Colonização Interna (JCl: 1936-1974) [Internal Colonisation Department], in Portugal, and by the Instituto Nacional de Colonización (INC: 1939-1971) [National Institute of Colonisation], in Spain. In fact, such a process was a privileged field of experimentation, in which the Iberian architects could cross the traditional practices with the modern conventions and technical innovations, in distinct scales of intervention, from the territorial planning to the construction detail, shaping solutions of different kind for the new settlements and also for the settler's house. The house was, thus, "the central element of the colonizing action" and its "typological election became a crucial matter of attention" [7].

This paper is focused on the rural house typology in the context of the Iberian agricultural colonization, as well as in the political and ideological framework that circumscribed it. The scope of inquiry includes seven colonies promoted by the $\mathrm{JCl}$ between the late-1930s and 1950s, and thirty-three pueblos constructed in the Tagus Valley under the INC action ${ }^{3}$ [8], between 1945 and 1965. It applies a comparative analysis that, through the cross-view of two case studies, the Boalhosa colony and the Puebla de Argeme, allows the study of the rural house as a model, a symbol and a mechanism of organization.

architects such as Aldo van Eyck, Giancarlo de Carlo, Alison Smithson, among others, became part of the group, ending up quite wider with an activity far beyond of what was originally purpose. ${ }^{3}$ Nearly 300 pueblos were built in the watersheds of the rivers Douro, Tagus, Guadiana, Guadalquivir and Ebro. 


\section{The framework of Iberian colonisation}

Both sides - Portugal and Spain - shared a common utopian vision for agrarian progress, based on scientific and technological improvements, the introduction of hydraulic systems of irrigation, mechanization and the experimental control of nature and the population in rural areas. The implications of such progress were also evident in the changed status of the settler into a small landowner, in order to avoid the exodus from countryside to city and to serve the authoritarian political interests of Salazar and Franco.

Although looking at the internal colonization as a political, economic and social strategy grounded on the same structural elements, such as the settler, the house, the settlement, and the land plot, each regime had a distinct ideological framework in which to place the ideal image of the rural landscape.

\section{The types of Iberian settlements}

In the Iberian colonization, the house was a structuring mechanism in the general organization of the settlement. In the Spanish case, such a settlement was a concentrated and generated autonomous pueblo, composed around a civic centre and with its physical limits clearly outlined. It was intended to establish a model able to provide the patterns of the urban quality of life, thus importing notions of urban planning to the rural structure, such as the grid, the hierarchy of streets, the city block, the square, the public space, the garden or the diversity of housing typologies.

The social factors (education, health, leisure and community living, proximity to administrative services, infrastructure network) were also determinant in this choice, to the detriment of the purely economic factors (higher productivity or farm surveillance) associated with dispersed schemes.

In addition, the constant variation of the agricultural plots, resulting from an intensive irrigated crop that will form the basis of the colony's sustainability, was not suitable for dispersed housing proposals. More precisely, tierras en excesso [lands in excess], resulting from the expropriation of latifundia, were divided into family units of cultivation (around 4-8 ha), which would define the size of each pueblo, roughly between 80 and 150 houses [8].

The number of settler's houses, their typology and associated land plots were predefined in the planning phase and differentiated from the ones dedicated to the obreros - who worked in the lands that remained under the landowner propriety. A hierarchical and independent system of roads separated human from cattle circulation, therefore responding to hygiene requirements promoted by the INC.

Positioned within a $2,5 \mathrm{~km}$ radius of influence, (the so-called modulo carro [cart module], which corresponded to the most convenient route between the dwelling and the associated land), the pueblos were "all identical in importance and without hierarchy levels" [9: 464]. Together, they formed a balanced web near the large areas of private cultivation, which itself would benefit from such an organization. Inside this circle of influence, only around a third of the land was allotted to the settlers, which would have direct consequences for the distribution and extent of the houses to be built.

In the Portuguese agrarian colonies the type of settlement was diverse and subject to transformation. Starting with the experience of dispersed settlements, with deeper

\footnotetext{
${ }^{4}$ Which Soto further describes as a "non-hierarchical homogeneous polynuclear system" [ibid.].
} 
consequences in terms of isolation and subsequent abandonment of the colonies ${ }^{5}$, the structures evolved into semi-dispersed or pro-concentrated [5: 112] types, ending up in schemes of concentrated housing motivated by factors of proximity with the work places, equipment and basic infrastructure, as well as by the needs of a neighbourhood, in which isolated houses were replaced by row houses and street fronts. When present, the civic centre was much less dense and expressive than in the Spanish case, with fewer communitarian services as well, usually located in the intersection of the paths that gave access to the land plots.

Each agrarian colony constituted either a single autonomous entity or was organised into one or more chief settlement, where were concentrated the main infrastructure, church, post office, school and the house of the technicians, and which were associated with smaller "satellite nuclei". The land plots, of regular configuration, were distributed over the territory, forming further villages [10: 35].

This idea of a network would be used in the innovative "CIAM village", now under a modernist approach that proposed a transitional scale between the local, regional and national. In the colonies with more than one settlement, a hierarchized network was often established, in which the core settlement concentrated the civil equipment and services.

One of the "legal entities" established in the colonization process was the casal agrícola [smallholding], which encompassed a house, associated agricultural facilities, tools, animals for traction and pasture, and connected land that ensured the economic self-sufficiency of the family. As a result, the house was generally standing alone within the land parcel, manifesting the close connection between the family and the property, through an inalienable and indivisible contract. This relationship of indivisibility is also present in the Spanish case between the urban unit (a lot built within the pueblo) and the agricultural unit (land parcel for cultivation and irrigation), which is sized according to the productive capacity of the family.

The number of casais was determined according to the general planning approach in relation to the total area of cultivation and consequent parcelling, regarding the type of soil and its agricultural suitability, topography, accessibilities or infrastructure. Depending on the colonies, the size of the land parcel varied between 5 ha and 25 ha, part of it being destined for reforestation.

\section{Two settlements under study: Boalhosa and Puebla de Argeme}

These settlements represent an important stage in the process of Iberian colonization in general, and for architectural experimentation in particular. They were a point of arrival from the previous experience, which corroborated the policies defined by the $\mathrm{JCI}$ and INC. Even with several transformations, Puebla de Argeme (1957) helped to shape the main guidelines of the INC during the most productive period of its activity. In Boalhosa (1946/1958), the last Portuguese colony, the type of settlement and the typology of the casal agrícola offered a singular solution remarkable among the other conventional schemes, testing new approaches that overcame less well-achieved proposals.

\footnotetext{
${ }^{5}$ Oral information of the current inhabitants of the Agricultural Colony of Miracles, family of settlers, 2017.
} 


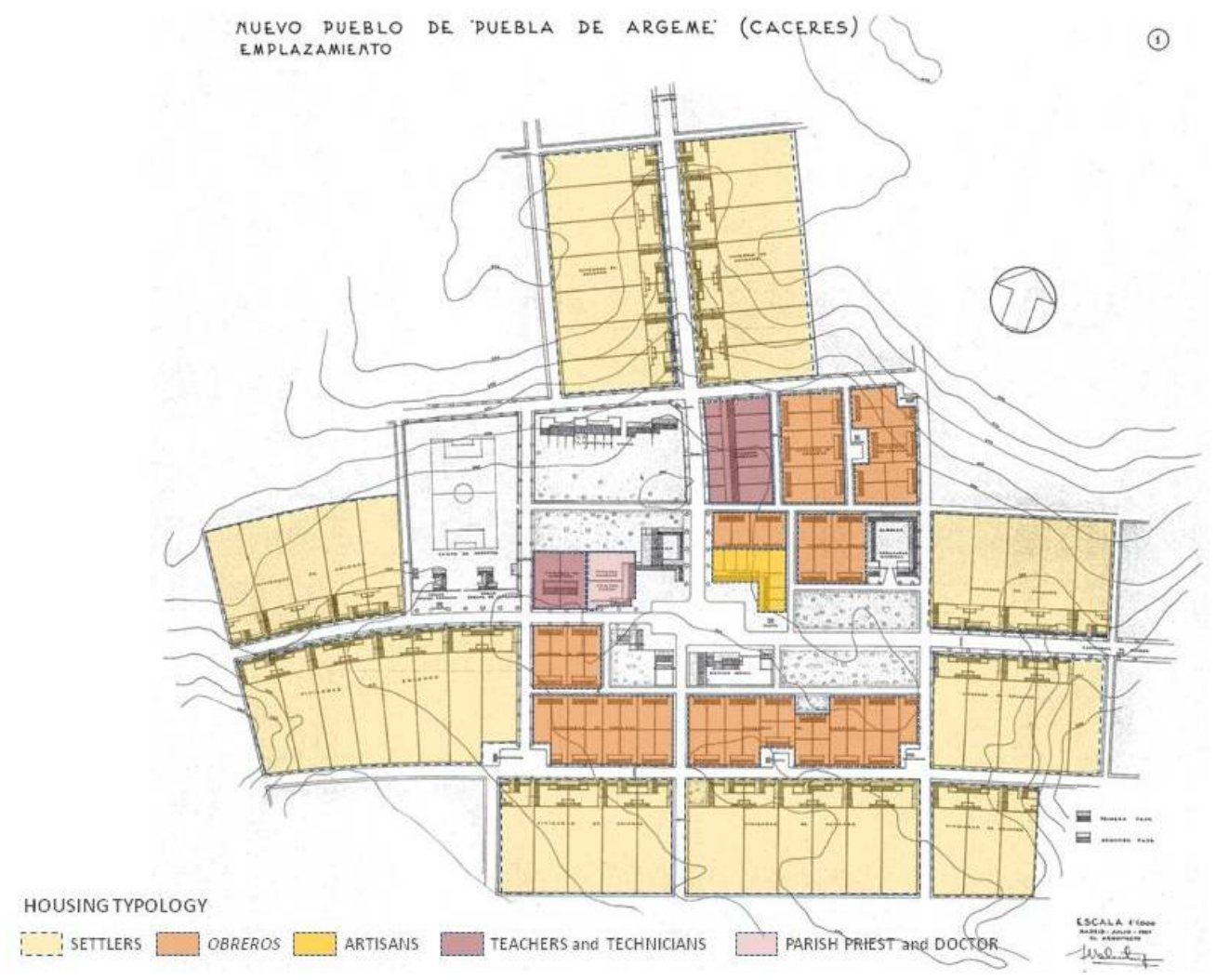

Fig. 1. Plan of Puebla de Argeme. Source: [11: 15 Plano-A.pdf], housing typology scheme by the authors of this paper.

\section{The type of settlement}

The implementation of different schemes of settlement in the lberian region led to a set of decisions that were reflected both the organization of civic centres and the typology of the houses (more urban under the concentrated scheme or more rural in the option of dispersed settlement), and the circulation web that supports the interconnections between field $\rightarrow$ workable land $\rightarrow$ lot $\rightarrow$ house $\rightarrow$ agricultural annexes.

Like almost all the pueblos situated in the Tagus basin, Puebla de Argeme is located on flat topography and is characterized by a regular layout, in accordance with the INC's Circulars, characterized by a clearly modern orthogonal grid of streets, lots, blocks and central square. The pueblo's structure is organized into a sequential composition of urban design elements: square (civic centre) $\rightarrow$ street (layout ordering element) $\rightarrow$ lot (association module) $\rightarrow$ housing (patio + annexes) $\rightarrow$ block (grouping unit)

The civic centre was a mandatory requirement of the programme, materialized in a geometric square, with fountain, urban furniture and vegetation, located in a central area, where two crossed axes structure the urban pattern and delimit the urban fronts and hierarchical circulations, in which dwellings are situated. Together with the town hall and the church, the centre included artisan shops in a portico, and the social building (since this village was planned for 200 inhabitants).

In the original plan, designed by Germán Valentín-Gamazo, the programme comprised 51 dwellings for settlers and 82 for obreros. However, given the INC's 
strategy to set up a group of small agricultural owners, this programme would be reformulated in a second phase, increasing the houses for settlers to 120 in number.

Deployed on rugged and irregular topography, Boalhosa offers a distinct type of settlement. In fact, the layout depends on the natural characteristics of the land and landscape, defining an organic scheme in a fan shape opened to the south slope offering a broad view over the agricultural fields and protected from the north winds by woodland and trees. The original plan included several nuclei, but only Vascões was built for a set of 30 casais, occupied in 1958.



Fig. 2. Agricultural Colony of Boalhosa, 1959.

Source: Archival fund JCI/ DGADR

The facilities and services, located at the convergence of the lateral access streets, at the highest point of the colony, were limited to the primary school, the teacher's house and the planned but unbuilt church and medical post. The programme also included a community oven, a communal warehouse, later expanded to offices and guard house, and a viewpoint in a peripheral position.

The streets are parallel, following the contour lines in terraces, with the buildings aligned at the highest points and the gardens sloping down towards the lowest points. 
This matrix presents a profile embedded in the natural topography, constituted as: street $\rightarrow$ casal agrícola $\rightarrow$ land plot. Moreover, the east-west orientation of the streets provides simultaneous accesses, on the one hand, to the agricultural warehouses standing at the north, and on the other to the plots and gardens located to the south, in which the dwelling fronts are positioned.

\section{The housing attributes}

The implications of these settlement schemes were significant in the architectural definition of the dwellings. In both cases, the programme, outlined for housing a familysettler with 3-4 children, introduced a kind of stable matrix: a common kitchen-room with fireplace, a small storage room, a room for the couple (guaranteeing their intimacy), a room for boys and another for girls, thus assuring the moral requirements. However, the formalization and image of such matrix, volumetric composition and functional organization of the domestic space, had differences on each side of the border.

Thereby, in the Spanish pueblos there is a formal unity and a coherence of language between housing and facilities, probably resulting from two different aspects: firstly, a single architect was responsible for the definition of the plan, from the scale of the urban design to the architectural composition and construction details, and secondly, the short time period between the project phase and the building work. In addition, the systematic geometry of volumes and the use of white walls, where we can detect an ambiguity between the image of Spanish southern architecture, generalized by the INC, with apparently few links to the local vernacular tradition, and an attempt towards a rationalist architecture. Still, the instructions of the INC to keep the same formal composition for the same group of pueblos did not undermine project options, defined in the general plan, for creating specific qualities in each of them.

In the agricultural colonies, there is a clear difference between the modernity of the facilities and the tendency to approach a traditional rural image of the houses, supposedly invoking the aesthetical codes of the settlers. This does not mean, however, that the language of these houses followed the regional patterns of the vernacular architecture. On the contrary, even using regional materials, such as stone in the North and the whitewashed walls in the South, the house is a reinvention nearer to the bourgeois housing image, thereby giving a new dimension of the settler as a small landowner.

In Puebla de Argeme, "the typologies adopted, with regard to house-dwelling, will not be a direct consequence of peasant practice on the subject, but a clear derivation from the rational and independent house, in which the internal distribution already follows urban criteria" [7]. Here, the typical land plot, housing and agricultural annexes, with a working patio that articulates both constructions, is the modular element in the urban fabric. The experimental nature of this typology, resulted in the introduction of the vegetable garden into the urban structure, as well as in the over dimension of the lots. They were also organized in blocks of a single lot, allowing the separation of access to the house and the garden.

Two types of housing were associated in pairs, with a single floor comprising 3 or 4 bedrooms, with a small entrance hall. Regarding the traditional scheme, the upgrade comes in the space of the kitchen being independent from the living-dining room, and the sanitary facilities included from the beginning. Nevertheless, this solution was subsequently abandoned and reshaped, by subtracting the vegetable garden and dividing the lot, with implications in terms of the hierarchy of access, the configuration of the block streets and the volumetric density of the settlement. This variation of the 
plot did not affect the original housing, changing only the access that now is direct from the street, rather than the internal porch. A new typology was created in the expansion phase of the plan, with clear separation between the sleeping area and the daily social area - in which the living room and the dining room feature separately. This functional organization transfers the rationalization of the modern urban housing to the rural experience.



Fig. 3. Puebla de Argeme (province of Cáceres).

Photo: (c) Alexandra Cardoso, 2017.

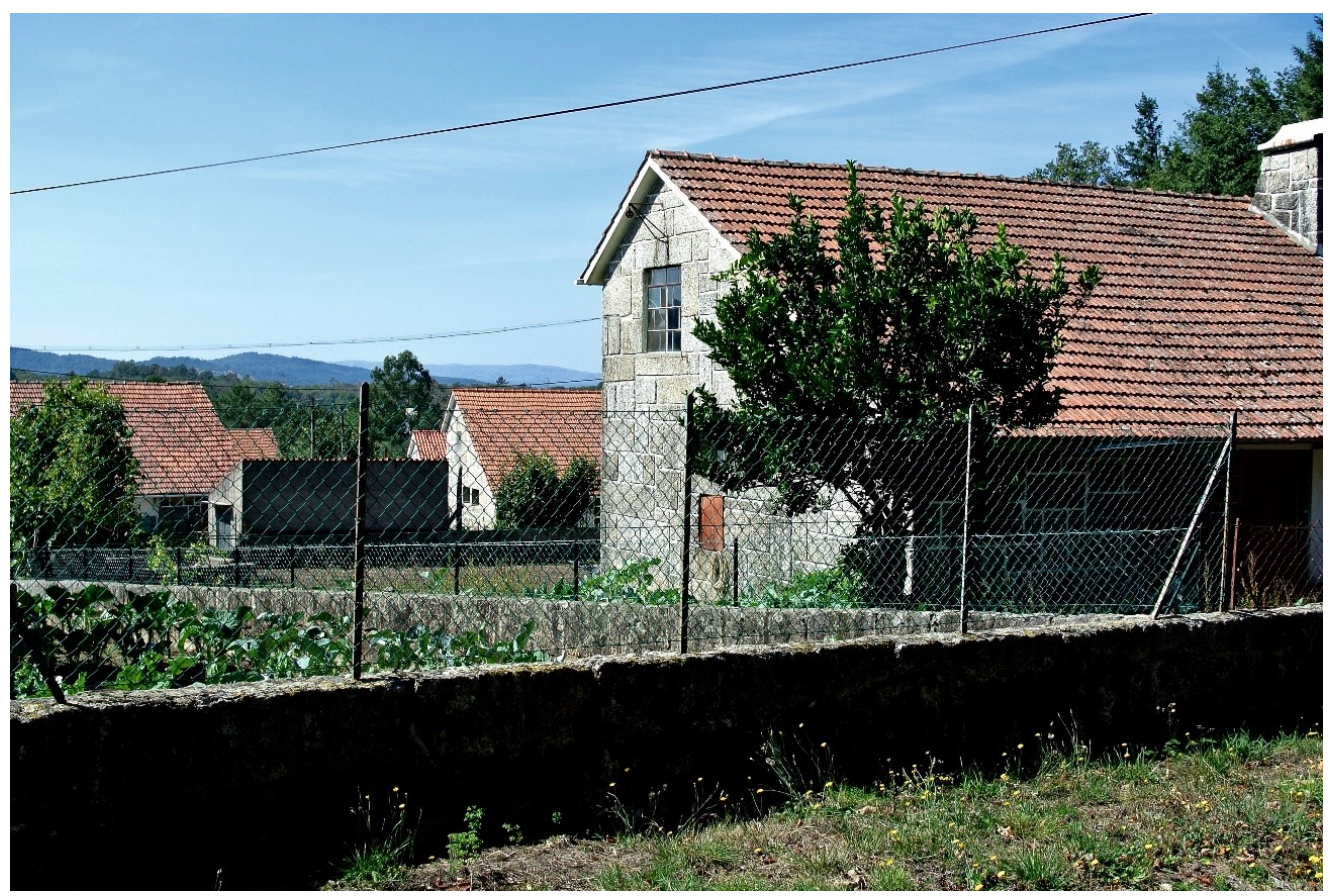

Fig. 4. Agricultural Colony of Boalhosa: Vascões nucleus (Paredes de Coura).

Photo: () Rute Figueiredo, 2017. 
In Boalhosa, the streets are defined by semi-detached houses, densifying the structure of the settlement. Here, the built-up set, grounded on a rectangular base, distinguishes the specificities of the programme in the facades: in the north, the organic composition of the facade in stone delimits the rural front of the agricultural annexes, and the areas for animals and carts; the south façade has a rational draw that reflects the internal organization. The asymmetry of the gable roof, and uneven floors reinforce such intention. This solution followed the JCl's guidelines, concentrating the housing, the stable and the agricultural annexes in a single volume. Hygienic concerns are also present here, though the integrated porch tends to blend the domestic space with the agricultural and livestock area.

The houses are equally distributed in the settlement, have the same image and are served by two accesses: one, in the upper street, leads to the porch (with a mezzanine for hay storage), the stable, the barn and also to the house; the other, in the down street, accesses the vegetable garden in the foreground and the house in a second plan. The strict concentration of functions in a single volume confined the organization of the interior space, with the social area limited to the kitchen and crossed by the circulation. This programme is complemented by a room on the ground floor, toilet facilities, and two rooms on the first floor.

\section{"The evolutive house" and the processes of appropriation}

In Spain, the vivienda crecedera [evolutive house] was a solution widely promoted by the INC. The housing expansion through addition, was defined during the project phase, in order to take into account the couple's growing number of children. In this process, it is important to note that the annexes included in the lot could also grow in order to accommodate the increase of agricultural parcels acquired by the settlers. This expansion was generally related to family increase or the addition of "production units" (= father's labour + sons/ages + daughters/ages, except the mother, exclusively dedicated to the domestic activities).

In Portugal, although discussed by the $\mathrm{JCl}$, the notion of casal agrícola was not able to be defined under an expandable perspective [12]. This question was, however, an important topic discussed by the Portuguese CIAM team, whose members proposed an expandable scheme with variants added to the type of interior organization, considering the family needs, with appropriation of strategically positioned empty spaces.

This debate on the expandable house cannot be isolated from the practical transformations introduced by the settlers themselves inside their own houses. From the survey already made, it can be seen that, on both sides, of the border, settlers expanded the housing by appropriating the spaces originally dedicated to agricultural use. While in Spain the organization of the lot allows expansion or even the construction of a second dwelling, in the Portuguese case, such expansion is contained and determined by the requirements of the original volume.

\section{Final remarks}

The solutions offered by Boalhosa and Puebla de Argeme were here taken as the nodal point, in which the several paths identified as important guidelines for the construction of a colonial culture had converged. Firstly, it pointed out some of JIC and INC'S directives, such as family units for agricultural development, the location of the workable land and the settlement typology. Secondly, this moment defined a model of a new rural 
housing - key element of the colonization - which was able to reflect the political and ideological strategies of two authoritarian regimes, as well as to disseminate new trends in architecture culture, in an exercise of organization of the rural way of life. Both cases reinvented rural conventions and a system of specific practices of appropriation/evolution that challenged the traditional approaches of functional organization, image and quality of rural settlements. We believe this reinvention contributed, in several aspects, to retain the $2^{\text {nd }}$ and $3^{\text {rd }}$ generation of settlers in these settlements, no longer devoted to the principles of agrarian practice, but still keeping the identity of the physical legacy left by colonization.

\section{Acknowledgements}

The presentation of this work was funded by national funds through FCT - Fundação para a Ciência e a Tecnologia, I.P., within the project UID/EAT/04041/2016 and it is based on the research conducted under the project MODSCAPES - Modernist Reinventions of the Rural Landscape, a collaborative research project funded under the HERA - Humanities in the European Research Area 3rd Joint Research Programme dedicated to "Uses of the Past" (20162019). This project has received funding from the European Union's Horizon 2020 research and innovation programme under grant agreement $n^{\circ} 649307$.

\section{Short resumes}

Alexandra Cardoso. Architect (FAUP, 1994). She has been working in the field of architectural theory and criticism as an affiliated researcher of Centro de Estudos Arnaldo Araújo (FCT uRD 4041). She was involved in several FCT projects: "The 'Popular Architecture in Portugal'. A Critical Look" (2010-2013); "Photography, Modern Architecture and the Escola do Porto: Interpretations around Teófilo Rego Archive" (2013-2015); "Portuguese Participation in CIAM X" (2014); "Southern Modernisms" (2014-2015). Currently, she is member of MODSCAPES - Modernist Reinventions of the Rural Landscape (HERA.15.097)

Alexandra Trevisan. Graduate and MSc in History of Art and PhD in Architecture. She is a fulltime tenured assistant professor at ESAP. She also is an affiliated researcher of the Architectural Studies group of CEAA (FCT URD 4041). She was PI of the FCT project "Photography, Modern Architecture and the Escola do Porto: Interpretations on Teófilo Rego Archive" (2013-2015) and member of the FCT research project "Southern Modernisms" (2014-2015). Currently, she is member of MODSCAPES - Modernist Reinventions of the Rural Landscape (HERA.15.097)

Rute Figueiredo. Architect (FAUTL) and architectural historian (M.A. in Art History), she holds a $\mathrm{PhD}$ in Architectural History and Theory from the ETH Zurich. Author of the study Architecture and Critical Discourse in Portugal 1893-1918, she coordinated the FCT R\&D project The Site of Discourse. Rute has presented her work at national and international congresses and has held research grants from the FCT, D-ARCH/ETH Zurich, and SNSF. She is researcher at CEEA/ESAP, where she has been working on the HERA project MODSCAPES (research fellowship), and currently at the Université Rennes2.

Maria Helena Maia holds a PhD in Modern Architecture and Restoration (ETSA/UVa). She is a full-time tenured assistant professor at ESAP - Escola Superior Artística do Porto. She also is an affiliated researcher of the Arnaldo Araújo Research Center (FCT uRD 4041). She has been publishing on architectural theory and history area, among which two were awarded publication prizes, and participated in several FCT research projects, such as "The 'Popular Architecture in Portugal'. A Critical Look" (2010-2013). Currently, she is one of the PIs of the ongoing project MODSCAPES - Modernist Reinventions of the Rural Landscapes (HERA.15.097) 


\section{References}

1. MOTA, N. 2012. "The Vernacular in Dubrovnik, 1956: Fetishism or Commitment?" in A. Cardoso, J.C. Leal, M.H. Maia (eds.). Surveys on Vernacular Architecture. Their Significance in $20^{\text {th }}$ Century Architectural Culture, (Proceedings of the CEAA colloquium, Porto, 17-19 May 2012), Porto, Centro de Estudos Arnaldo Aráujo: 356-370.

DOI: https://doi.org/10400.26/20650

2. MAIA, M.H.; CARDOSO, A. 2014. "Portuguese in CIAM X", in P. Marcolin, J. Flores (eds.). $20^{\text {th }}$ Century New Towns. Archetypes and Uncertainties, (Proceedings of the CEAA colloquium, Porto, 22-24 May 2014), Porto, DARQ/ESAP - Centro de Estudos Arnaldo Aráujo: 193-213. DOI: https://doi.org/10400.26/19941

3. LIMA, V.; TÁVORA, F.; FILGUEIRAS, O.L. et al. 1959. "Plano de uma Comunidade Rural" [Plan for a Rural Community], CIAM Team Porto (Portuguese delegation to CIAM X Congress, Dubrovnik), Arquitectura, $\mathrm{n}^{\circ} 64$.

4. SINDICATO NACIONAL DOS ARQUITECTOS (eds.) 1961. Arquitectura Popular em Portugal [Popular Architecture in Portugal], Lisbon

5. LOBO, V.; ANTUNES, A.M. 1960. Problemas Actuais da Pequena Habitação Rural [Current Problems of Small Rural Housing], Coimbra, Ministério das Obras Públicas. Direcção Geral dos Serviços de Urbanização. Centro de Estudos de Urbanismo.

6. GATEPAC, 1935. "La Arquitectura popular mediterránea" [Mediterranean popular architecture], AC-Documentos de Actividad Contemporánea, $\mathrm{n}^{\circ}$ 18: 33.

7. MONCLÚS, F.J.; OYÓN, J.L. 1983. "Colonización agraria y urbanismo rural en el siglo XX: la experiencia del Instituto Nacional de Colonización" [Agrarian colonization and rural urbanism in the twentieth century: the experience of the National Institute of Colonization], Ciudad $y$ Territorio, n 57-58: 67-84. DOI: http://doi.org/2117/19772

8. ALARCON, J.T. 1988. "Actuaciones del Instituto Nacional de Colonizacion 1939-1970" [Actions of the National Institute of Colonization 1939-1970], Revista Urbanismo (COAM) $n^{\circ} 3$ : 4-12.

9. SOTO, J.A.F. 2013. Aprendiendo de una arquitectura anónima: influencias y relaciones en la arquitectura española contemporánea: el INC en Extremadura [Learning from an anonymous architecture: influences and relationships in contemporary Spanish architecture: the INC in Extremadura], PhD Thesis, E.T.S. Arquitectura (UPM).

10. CALDAS, J.L.C. 1988. Política de colonização interna. A implantação das colónias agrícolas da $\mathrm{JCl}$ [Policy of internal colonization. The deployment of JCl's agricultural colonies], PhD Thesis, Instituto Superior de Agronomia, Universidade Técnica de Lisboa.

11. CALZADA PÉREZ, M. et al. 2007. Pueblos de colonización II. Guadiana y Tajo, (Itinerarios de arquitectura: 4), Córdoba, Fundación Arquitectura Contemporánea.

12. PINTO, A.M. 1938. "Parecer referente a dois projectos de colonização interna" [Opinion on two internal colonization projects], Diário das Sessões, $10^{\circ}$ Suplemento, 29 October. 